\title{
Determinants of stunting among children aged 0-59 months in Nepal: findings from Nepal Demographic and health Survey, 2006, 2011, and 2016
}

\author{
Ramesh P. Adhikari ${ }^{1 *}$ (D) Manisha Laxmi Shrestha ${ }^{2}$, Ajay Acharya ${ }^{3}$ and Nawaraj Upadhaya ${ }^{4}$
}

\begin{abstract}
Background: Stunting is one of the most commonly used indicators of child nutrition and health status. Despite significant efforts by the government and external development partners to improve maternal and child health and nutrition, stunting is consistently high in Nepal. This paper assesses the potential determinants of stunting among children aged 0-59 months using the last three successive Nepal Demographic and Health Surveys (NDHS).

Methods: We used three nationally representative cross-sectional household surveys, known as the NDHS- 2006, 2011 and 2016. Logistic regression was used to identify the potential determinants of stunting. The sub sample for this study includes $n=5083$ in 2006, $n=2485$ in 2011, and $n=2421$ in 2016.

Results: Rates of stunting decreased from nearly 50\% in 2006 to about 36\% in 2016. The prevalence of stunting was higher among children from larger families (51.0\% in 2006, $41.1 \%$ in $2011,38.7 \%$ in 2016), poor wealth quintile households (61.2\% in 2006, 56.0\% in 2011, 49.2\% in 2016), and severely food insecure households (49.0\% in 2011, $46.5 \%$ in 2016). For child stunting, the common determinants in all three surveys included: being from the highest equity quintile (OR: 0.58 in 2006, 0.26 in 2011, 0.28 in 2016), being older (OR: 2.24 in 2006, 2.58 in 2011, 1.58 in 2016), being below average size at time of birth (OR: 1.64 in 2006, 1.55 in 2011, 1.60 in 2016), and being affected by anemia (OR: 1.32 in 2006, 1.59 in 2011, 1.40 in 2016).

Conclusions: This study found that household wealth status, age of child, size of child at time of birth, and child anemia comprised the common determinants of stunting in all three surveys in Nepal. Study findings underscore the need for effective implementation of evidence-based nutrition interventions in health and non-health sectors to reduce the high rates of child stunting in Nepal.
\end{abstract}

Keywords: Children, Stunting, Nepal, Determinants

\section{Background}

Child malnutrition remains a major public health problem globally. Malnutrition can take the form of stunting (height-for-age and/or weight-for-height) and underweight (weight-for-age); however, stunting is the primary form of malnutrition seen throughout the world $[1,2]$. Stunting in early life is associated with adverse functional consequences, including poor cognition and

\footnotetext{
* Correspondence: rameshadhikaria@gmail.com; rpadhikari@hki.org

${ }^{1}$ Padma Kanya Multiple Campus, Tribhuvan University, Kathmandu Nepal and Helen Keller International Nepal, Lalitpur, Nepal

Full list of author information is available at the end of the article
}

educational performance, low adult wages, lost productivity, and chronic disease when accompanied by excessive weight gain later in childhood [3-5]. While the consequences of stunting are clear, its causes are more complex [6]. Direct factors contributing to stunted growth and development include poor maternal health and nutrition, inadequate infant and young child feeding practices, micronutrient deficiencies, and infections [7]. The Sustainable Development Goals (SDG) identified stunting, along with other nutrition indicators, as a target to reduce global malnutrition; meeting this goal

C The Author(s). 2019 Open Access This article is distributed under the terms of the Creative Commons Attribution 4.0 International License (http://creativecommons.org/licenses/by/4.0/), which permits unrestricted use, distribution, and reproduction in any medium, provided you give appropriate credit to the original author(s) and the source, provide a link to the Creative Commons license, and indicate if changes were made. The Creative Commons Public Domain Dedication waiver (http://creativecommons.org/publicdomain/zero/1.0/) applies to the data made available in this article, unless otherwise stated. 
demands renewed and concerted efforts focused on disparity [8].

Globally, approximately 155 million children under 5 years suffer from stunting, with an estimated one million associated child deaths annually. Among the regions of the world, Africa and Asia share the highest burden of all forms of malnutrition. In 2017, nearly two out of every five stunted children lived in Southern Asia [9]. Nepal is one of only ten countries in the world where more than half of children under five suffer from some form of malnutrition [10]. According to the $2016 \mathrm{Nepal}$ Demographic Health Survey, 36\% of children under five suffered from stunting. Previous studies in Nepal have identified several common determinants of stunting, including child sex, age, birth weight, birth order, number of siblings, wealth index, mother's education, mother's body mass index, and access to health care [11-13]. The Nepal government identified nutrition as one of the key priority areas for national development. In 2012, the Nepal government developed a multi-sector nutrition plan involving different line ministries to implement an evidence-based nutrition intervention throughout health and non-health sectors. As a result, Nepal has made significant gains in health and nutrition indicators, including stunting, despite being in social, economic and political transition [14], and being one of the poorest countries in South Asia. Nevertheless, decreases in stunting stalled between 2012 and 2017. To meet the global target by 2025, Nepal needs to continue to reduce stunting by $3.9 \%$ annually [15].

The purpose of this paper is to determine the prevalence and associated factors of child stunting in the last 15 years in Nepal using nationally representative data from the Nepal Demographic and Health Surveys (NDHS) 1996-2016. While previous studies attempted to explore determinants of stunting, each only reported data from a single year. Currently, there is insufficient evidence on trends and determinants of stunting from nationally representative surveys in Nepal, thus limiting long-term policy formulation and planning. Hence, assessing the trends and factors associated with stunting will provide insights into the effectiveness of the implemented program and will assist policy makers and program developers in designing new and effective programs that target groups most at-risk.

\section{Methods}

This paper uses data from the 2006, 2011, and 2016 NDHS, a nationally representative cross-sectional household survey. This dataset includes information on a variety of health topics, as well as socio-economic and demographic information. The risk factors have been classified into demographic factors, maternal nutrition factors, and child nutrition factors. The NDHS surveys used a two stage selection process; initially, enumeration areas (clusters) were selected with probability proportionto-size (PPS) methodology and next, households were selected with an equal probability systematic selection from each sample cluster. The sampling details for this survey have been documented in the full NDHS report [16]. In 2006, height and weight information for a total of 5295 children was collected from 8707 interviewed households. Similarly, in 2011, 2603 children's height and weight information was collected from 10,826 interviewed households, and in 2016, a total of 2428 children's information was collected from 11,040 interviewed households. Some cases were excluded because their height and weight measurements were outliers ( $n=212$ in 2006, $n=118$ in 2011, and $n=7$ in 2016). Thus, the final sample sizes for the analyses in this paper were $n=5083$ in 2006, $n=2485$ in 2011, and $n=2421$ in 2016. [16].

Stunting, the single outcome variable, was measured based on height-for-age $\mathrm{z}$-scores $<-2$ standard deviation. The NDHS calculated the height-for-age $\mathrm{z}$-scores based on the 2006 World Health Organization (WHO) growth standards. These scores were used for the analysis [17]. Based on the local context and prior studies, household, maternal, and child characteristics were included as potential determinants of stunting in Nepal. Household characteristics included family size, headship of the household, caste/ethnic group (Dalit, Muslim, Janajati, other Terai caste, Brahmin/Chhetri, others), wealth quintile (based on NDHS wealth quintiles), place of residence (urban or rural), ecological zone (mountain, hill, or terai), household food security status (food secure, mildly food secure, moderately food insecure, or severely food insecure), and access to drinking water and a toilet (improved or unimproved). Maternal characteristics included the mother's age, years of schooling, employment status (currently employed or not), BMI (underweight with a BMI $<18.5$, or not), anemia (anemic or not), and number of living children. Likewise, child characteristics included age and sex of the child, birth order, size at time of birth (average or larger or below average), and anemia (anemic or not).

The NDHS used the same questions as the Household Food Insecurity Scale (HFIAS), which was originally developed by the United States Agency for International Development (USAID) Food and Nutrition Technical project to measure household food security status. These questions focused on the severity and frequency of food insecurity in the household units based on the 30 days preceding the survey. Based on responses to these questions, four categories were developed based on the HFIAS measuring guidelines: food secure, mildly food secure, moderately food insecure and severely food insecure [18]. Access to piped drinking water was defined as "improved" water access, while all other sources were 
defined as "unimproved". Likewise, access to a toilet was defined as "improved" if the households had flush/pour toilets to piped sewer systems, septic tanks and/or pit latrines, ventilated improved pit latrines with slabs, and/or composting toilets. Access to other types of toilets were considered "unimproved".

The NDHS collected blood samples to measure mother and child anemia using HemoCue. Children were considered anemic if their hemoglobin levels were $<11.0 \mathrm{~g} / \mathrm{deci}-$ liter. Likewise, mothers were considered anemic if their hemoglobin levels were $<12.0 \mathrm{~g} /$ deciliter for non-pregnant mothers and $<11.0$ for pregnant mothers. Mothers were included if they had ever been married, were not currently pregnant, and had not given birth in the previous 2 months. Exclusion criteria included outliers in BMI, height, and weight measurements [16]. For the national representation of the sample, the analysis was performed by applying sampling weights. Descriptive, univariate, bivariate, and multivariate analyses was performed. Mean z-scores and standard deviations were calculated for height-for-age. Logistic regression models were used to identify the possible determinants of stunting. All analyses were performed in Stata version 14.

\section{Results}

This study included 5083 children from the 2006 NDHS, 2485 children from the 2011 NDHS, and 2421 children from the 2016 NDHS. In all three surveys, more than a quarter of the children were from Janajati caste/ethnic groups, more than half were from the Terai region, and about $60 \%$ were between 24 and 59 months. With regard to mothers' education, more than half of the mothers sampled had no schooling in 2006 and 2011; however, this was down to $36 \%$ in 2016 (Table 1).

\section{Prevalence of stunting}

The mean z-scores for stunting (height-for-age) showed slight improvement between 2006 and 2016 (-1.92 in 2006 and -1.29 in 2016). Likewise, the proportion of child stunting decreased from $49.3 \%$ in 2006 to $35.8 \%$ in 2016. The proportion of stunting was higher among larger families, children from the Dalit caste/ethnic group, households from the poorest wealth quintile, children residing in rural and mountain regions, and children from severely food insecure households (Table 2).

In all three surveys, the proportion of child stunting decreased as the number of years of mothers' schooling increased. For example, the prevalence of child stunting was $45.3 \%$ among children whose mothers had no education, compared with $22.7 \%$ among children whose mothers had 10 or more years of schooling in 2016. Furthermore, the increases the number children living in a household also increase the likelihood of stunting. For instance, in 2016, the prevalence of stunting was $28 \%$ in single child households compared with $46.2 \%$ for the households with 3 or more children. The chances of stunting were also greater among children with anemic mothers. Child characteristics such as age, sex, birth order, birth size, and hemoglobin level were found to be determining factors for stunting in all three surveys. Stunting increased with increases in age and birth order. Likewise, small size at birth, female gender, and low level of blood hemoglobin (anemia) increased the likelihood of stunting in children (Table 2).

\section{Factors associated with stunting}

The adjusted odd ratios in Table 3 show that in all three surveys, wealth quintile, age of child, size of child at birth, and anemia were significant determinants of stunting in children. In the adjusted model, we adjusted for household, maternal, and child characteristics including family size, headship of the household, caste/ethnicity, wealth quintile, place of residence, household food security status, access to drinking water and a toilet, mother's age, mother's years of education, number of living children, mother's employment status, mother's BMI and anemia status, age and sex of child, birth order, size of child at time of birth, and child anemia status. In all three surveys, children in the richer and richest wealth quintile households were less likely to be stunted compared with children from the poorest quintile households. Likewise, in all three surveys, older children were more likely to be stunted than younger children (OR: 2.24 in 2006, 2.58 in 2011, 1.58 in 2016). Children who were below average size at time of birth were 1.6 times more likely to be stunted in all three surveys compared with children who were average size or larger at time of birth (OR: 1.64 in 2006, 1.55 in 2011, 1.60 in 2016). Similarly, children who suffered from anemia were more likely to be stunted in all three surveys (OR: 1.32 in 2006, 1.59 in 2011, 1.40 in 2016) (Table 3).

\section{Discussion}

This paper outlines the prevalence of stunting and associated risk factors among children under five in Nepal. Study findings suggest that stunting in Nepal has decreased over the last decade (mean decline of - 1.92 in 2006 to -1.29 in 2016). The Nepal government implemented the Multi-Sectoral Nutrition Plan (MSNP) in 2012 with the key objective of improving nutrition status among adolescent girls, pregnant and lactating women, and all children under 24 months. The MSNP is an evidence-based, cost-effective nutrition intervention that integrates both national and community priorities. The plan outlines the roles of key health, education, and agriculture sectors in implementing policies and strategies. Thus, decreases in stunting may be attributable to the implementation of the MSNP in Nepal $[14,15,19,20]$. 
Table 1 Socio-economic and demographic characteristics of children under 5 years and their mothers

\begin{tabular}{|c|c|c|c|c|c|c|}
\hline \multirow[t]{2}{*}{ Background characteristics } & \multicolumn{2}{|l|}{2006} & \multicolumn{2}{|l|}{2011} & \multicolumn{2}{|l|}{2016} \\
\hline & $\%$ & N & $\%$ & $\mathrm{~N}$ & $\%$ & N \\
\hline \multicolumn{7}{|l|}{ Caste/ethnicity } \\
\hline Dalit & 15.5 & 788 & 17.7 & 440 & 14.1 & 342 \\
\hline Muslim & 5.6 & 286 & 5.9 & 147 & 6.8 & 164 \\
\hline Janajati & 31.6 & 1608 & 32.0 & 794 & 27.3 & 661 \\
\hline Other Terai caste & 14.0 & 713 & 9.3 & 230 & 19.8 & 479 \\
\hline Brahmin/Chhetri & 28.4 & 1444 & 29.5 & 734 & 26.0 & 629 \\
\hline Other & 4.8 & 244 & 5.6 & 140 & 6.0 & 146 \\
\hline \multicolumn{7}{|l|}{ Wealth quintile } \\
\hline Poorest & 25.3 & 1285 & 25.8 & 640 & 20.5 & 496 \\
\hline Second poorest & 21.4 & 1086 & 20.5 & 510 & 21.8 & 528 \\
\hline Middle & 20.3 & 1032 & 23.4 & 582 & 22.7 & 549 \\
\hline Second richest & 18.1 & 921 & 16.9 & 421 & 21.7 & 526 \\
\hline Richest & 14.9 & 759 & 13.4 & 332 & 13.3 & 322 \\
\hline \multicolumn{7}{|l|}{ Ecological Zone } \\
\hline Mountain & 8.4 & 425 & 7.9 & 196 & 7.0 & 170 \\
\hline Hill & 41.3 & 2100 & 39.9 & 991 & 36.2 & 876 \\
\hline Terai & 50.3 & 2558 & 52.2 & 1298 & 56.8 & 1375 \\
\hline \multicolumn{7}{|l|}{ Year of schooling of mother } \\
\hline No schooling & 61.4 & 3119 & 50.5 & 1256 & 36.0 & 910 \\
\hline $1-5$ years schooling & 16.9 & 858 & 17.8 & 442 & 19.0 & 449 \\
\hline 6-9years schooling & 15.5 & 788 & 18.7 & 464 & 23.9 & 563 \\
\hline 10 and above years of schooling & 6.3 & 318 & 13.0 & 323 & 21.1 & 499 \\
\hline \multicolumn{7}{|l|}{ Age of child } \\
\hline Less than 6 months & 9.1 & 474 & 9.2 & 228 & 9.0 & 218 \\
\hline 6-11 months & 9.2 & 484 & 9.9 & 247 & 10.4 & 251 \\
\hline $12-23$ months & 18.7 & 970 & 19.6 & 489 & 21.1 & 512 \\
\hline 25-49 months & 63.1 & 3155 & 61.3 & 1521 & 59.5 & 1440 \\
\hline \multicolumn{7}{|l|}{ Sex of child } \\
\hline Boys & 51.2 & 2604 & 51.2 & 1273 & 52.0 & 1258 \\
\hline Girls & 48.6 & 2479 & 48.8 & 1212 & 58.0 & 1163 \\
\hline Total & 100.0 & 5083 & 100.0 & 2485 & 100.0 & 2421 \\
\hline
\end{tabular}

The study analyses identified significant determinants of stunting present across all three surveys; household wealth status, number of years of mother's schooling, age of child, size of child at time of birth, and child anemia were all associated with stunting. Children from the poorest households were more likely to be stunted than children from middle income, richer, and richest households. This reflects findings from a systematic review conducted in sub-Saharan Africa by Akombi and colleagues [21, 22]. Likewise, a study based on the Bangladesh Demographic and Health Survey 2011 similarly found that wealth index was significantly associated with child stunting [21, 22]. The study findings also indicate that mothers with ten or more years of schooling were $37 \%$ less likely to have stunted children than mothers with no education. This reflects results from studies demonstrating less child stunting among mothers with more years of education [23-28]. Reduced child stunting among more educated mothers might reflect better feeding and care practices among these mothers [29].

Findings indicate that children aged 24-59 months were at higher risk for stunting than children aged 0-23. This is consistent with findings from similar studies [30-32], and may be explained by the protective effect of breastfeeding. While most children in Nepal are 
Table 2 Prevalence of stunting (<-2SD) among children aged 0-59 months

\begin{tabular}{|c|c|c|c|c|c|c|}
\hline & \multicolumn{2}{|l|}{2006} & \multicolumn{2}{|l|}{2011} & \multicolumn{2}{|l|}{2016} \\
\hline & $\%$ & $\mathrm{~N}$ & $\%$ & $\mathrm{~N}$ & $\%$ & $\mathrm{~N}$ \\
\hline Total (mean z score and SD) & $49.3(-1.93 ; 1.3)$ & 5083 & $40.5(-1.66 ; 1.4)$ & 2485 & $35.8(-1.29 ; 4.9)$ & 2421 \\
\hline \multicolumn{7}{|l|}{ Household characteristics } \\
\hline \multicolumn{7}{|l|}{ Family size } \\
\hline Less than 5 & 43.2 & 1247 & 38.9 & 693 & 29.3 & 727 \\
\hline 5 and above & 51.0 & 3836 & 41.1 & 1792 & 38.7 & 1694 \\
\hline \multicolumn{7}{|l|}{ Headship of the households } \\
\hline Male & 48.7 & 4052 & 41.2 & 1828 & 36.2 & 1652 \\
\hline Female & 50.9 & 1031 & 38.7 & 657 & 35.0 & 769 \\
\hline \multicolumn{7}{|l|}{ Caste/ethnicity } \\
\hline Dalit & 56.5 & 788 & 47.0 & 440 & 38.7 & 342 \\
\hline Muslim & 56.6 & 286 & 31.0 & 147 & 37.2 & 164 \\
\hline Janajati & 44.9 & 1608 & 40.4 & 794 & 32.2 & 661 \\
\hline Other Terai caste & 50.3 & 713 & 45.9 & 230 & 42.3 & 479 \\
\hline Brahmin/chhetri & 47.8 & 1444 & 36.8 & 734 & 34.6 & 629 \\
\hline Other & 48.5 & 244 & 41.0 & 140 & 28.3 & 146 \\
\hline \multicolumn{7}{|l|}{ Wealth quintile } \\
\hline Poorest & 61.2 & 1285 & 56.0 & 640 & 49.2 & 496 \\
\hline Second poorest & 54.4 & 1086 & 45.7 & 510 & 38.7 & 528 \\
\hline Middle & 50.6 & 1032 & 34.5 & 582 & 35.7 & 549 \\
\hline Second richest & 39.7 & 921 & 30.5 & 421 & 32.4 & 526 \\
\hline Richest & 30.5 & 759 & 25.8 & 332 & 16.5 & 322 \\
\hline \multicolumn{7}{|l|}{ Place of residence } \\
\hline Urban & 35.8 & 619 & 26.7 & 217 & 32.0 & 1280 \\
\hline Rural & 51.0 & 4464 & 41.8 & 2268 & 40.2 & 1141 \\
\hline \multicolumn{7}{|l|}{ Ecological Zone } \\
\hline Mountain & 61.2 & 425 & 52.9 & 196 & 46.8 & 170 \\
\hline Hill & 50.2 & 2100 & 42.1 & 991 & 32.3 & 876 \\
\hline Terai & 46.2 & 2558 & 37.4 & 1298 & 36.7 & 1375 \\
\hline \multicolumn{7}{|l|}{ Household food security status } \\
\hline Food secure & NA & & 33.2 & 1061 & 29.2 & 991 \\
\hline Mildly food insecure & NA & & 41.2 & 305 & 35.9 & 557 \\
\hline Moderately food insecure & NA & & 45.6 & 577 & 42.0 & 623 \\
\hline Severely food insecure & NA & & 49.0 & 542 & 46.5 & 250 \\
\hline \multicolumn{7}{|l|}{ Access of drinking water } \\
\hline Unimproved & 51.2 & 1296 & 48.9 & 361 & 43.3 & 112 \\
\hline Improved & 48.4 & 3787 & 39.1 & 2124 & 35.5 & 2309 \\
\hline \multicolumn{7}{|l|}{ Access of toilet } \\
\hline Unimproved & 53.9 & 3659 & 45.0 & 1415 & 48.9 & 581 \\
\hline Improved & 36.9 & 1424 & 34.6 & 1070 & 31.7 & 1840 \\
\hline \multicolumn{7}{|l|}{ Maternal characteristics } \\
\hline \multicolumn{7}{|l|}{ Age of mother } \\
\hline $15-19$ & 33.6 & 333 & 27.9 & 170 & 37.4 & 194 \\
\hline $20-24$ & 45.4 & 1761 & 39.8 & 908 & 32.5 & 863 \\
\hline
\end{tabular}


Table 2 Prevalence of stunting (<-2SD) among children aged 0-59 months (Continued)

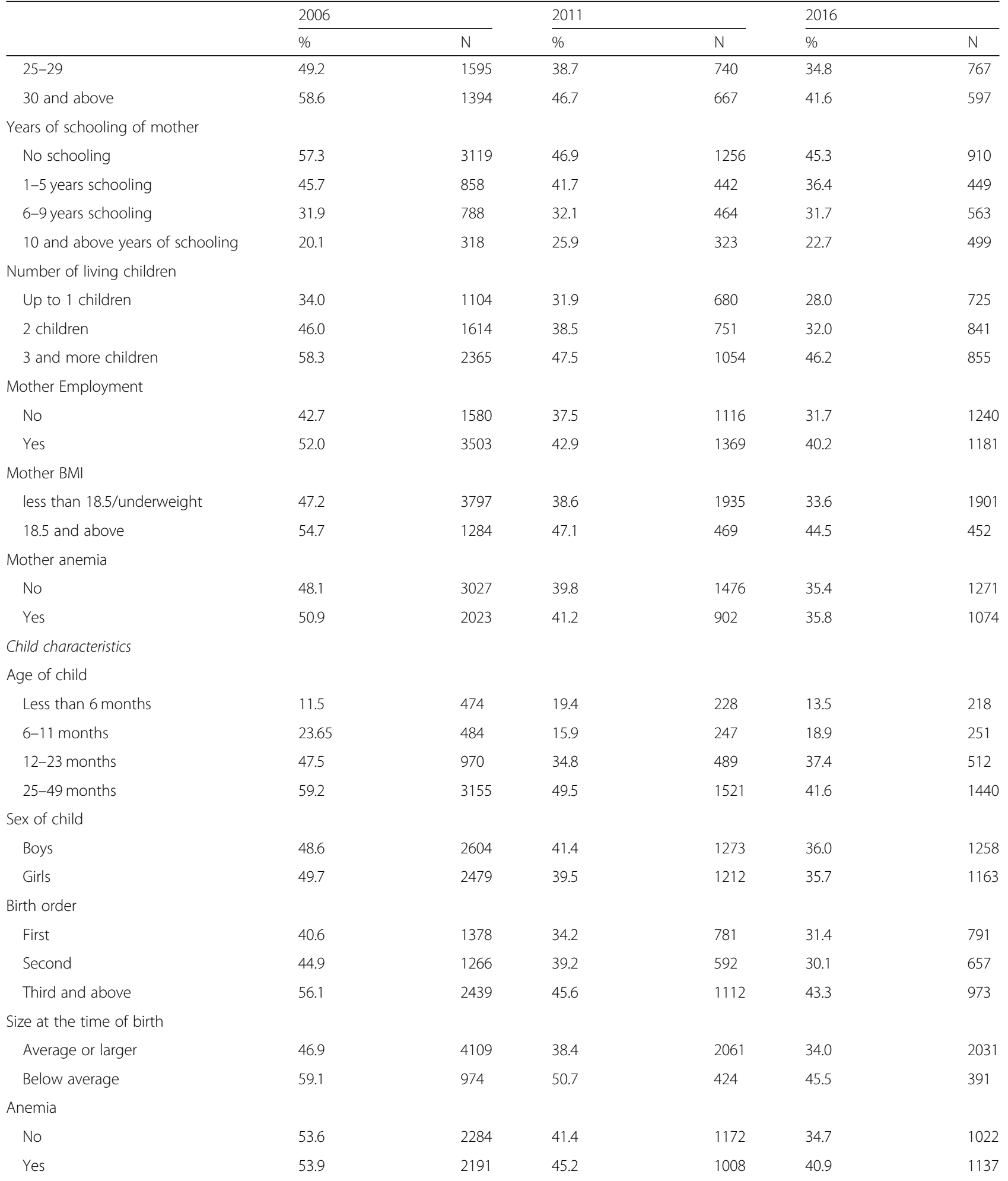


Table 3 Determinants of stunting in children aged 0-59 months

\begin{tabular}{|c|c|c|c|c|c|c|}
\hline \multirow{3}{*}{$\begin{array}{l}\text { Background characteristics } \\
\text { Household characteristics }\end{array}$} & \multicolumn{6}{|c|}{ Odd ratios of stunting (height for age $<-2 S D$ ) } \\
\hline & \multicolumn{2}{|l|}{2006} & \multicolumn{2}{|l|}{2011} & \multicolumn{2}{|l|}{2016} \\
\hline & $\begin{array}{l}\text { Unadjusted } \\
(\mathrm{OR}, \mathrm{P} / \mathrm{Cl})\end{array}$ & $\begin{array}{l}\text { Adjusted } \\
(\mathrm{OR}, \mathrm{P} / \mathrm{Cl})\end{array}$ & $\begin{array}{l}\text { Unadjusted } \\
(\mathrm{OR}, \mathrm{P} / \mathrm{Cl})\end{array}$ & $\begin{array}{l}\text { Adjusted } \\
(\mathrm{OR}, \mathrm{P} / \mathrm{Cl})\end{array}$ & $\begin{array}{l}\text { Unadjusted } \\
(\mathrm{OR}, \mathrm{P} / \mathrm{Cl})\end{array}$ & $\begin{array}{l}\text { Adjusted } \\
\text { (OR, P/Cl) }\end{array}$ \\
\hline Family size & $1.37^{* *}[1.16-1.62]$ & $1.15[0.95-1.38]$ & $1.01[0.86-1.40]$ & $0.87[0.62-1.21]$ & $1.52^{* *}[1.22-1.90]$ & $1.39^{*}[1.06-1.83]$ \\
\hline \multicolumn{7}{|l|}{ Headship of the households } \\
\hline \multicolumn{7}{|l|}{ Male (R) } \\
\hline Female & $1.09[0.91-1.31]$ & $1.01[0.82-1.24]$ & $0.90[0.71-1.14]$ & $0.85[0.64-1.14]$ & $0.95[0.77-1.17]$ & $1.06[0.84-1.35]$ \\
\hline \multicolumn{7}{|l|}{ Caste/ethnicity } \\
\hline \multicolumn{7}{|l|}{ Dalit(R) } \\
\hline Muslim & $1.00[0.74-1.35]$ & $1.21[0.82-1.80]$ & $0.50[0.30-0.85]$ & $0.55[0.27-1.14]$ & $0.94[0.60-1.47]$ & $1.04[0.61-1.78]$ \\
\hline Janajati & $0.63[0.48-0.83]$ & $0.73[0.53-0.99]$ & $0.76[0.56-1.04]$ & $0.89[0.61-1.29]$ & $0.75[0.53-1.08]$ & $1.01[0.69-1.47]$ \\
\hline Other Terai caste & $0.78[0.59-1.03]$ & $0.96[0.69-1.33]$ & $0.95[0.63-1.43]$ & $1.56[1.04-1.33]$ & $1.16[0.81-1.66]$ & $1.18[0.74-1.91]$ \\
\hline Brahmin/chhetri & $0.70[0.57-0.89]$ & $0.94[0.69-1.26]$ & $0.65[0.51-0.85]$ & $0.80[0.58-1.09]$ & 0.84 [0.60-1.17] & $1.08[0.72-1.61]$ \\
\hline Other & $0.72[0.35-1.50]$ & $0.80[0.36-1.77]$ & $0.78[0.48-1.29]$ & $0.96[0.39-2.37]$ & $0.63[0.37-1.05]$ & $0.60[0.26-1.36]$ \\
\hline
\end{tabular}

Wealth quintile

Poorest (R)

Second poorest

$0.76^{* *}[0.63-0.92]$

$0.87[0.65-1.18]$

$0.66^{* *}[0.50-0.88]$

$0.58^{* *}[0.39-0.87]$

$0.65^{* *}[0.49-0.87]$

$0.60^{* *}[0.43-0.85]$

Middle

$0.65^{* *}[0.51-0.82]$

0.84 [0.63-1.13]

$0.42^{* *}[0.30-0.57]$

$0.45^{* *}[0.29-0.68]$

$0.57^{* *}[0.42-0.77]$

$0.51 * * 0.36-0.73]$

Second richest

$0.59^{* *}[0.42-0.83]$

$0.35^{* *}[0.25-0.48]$

$0.30^{* *}[0.17-0.53]$

$0.49^{* *}[0.37-0.66] \quad 0.56^{* *}[0.37-0.85]$

Richest

$0.28^{* *}[0.22-0.35]$

$0.58^{*}[0.38-0.88]$

$0.27^{* *}[0.19-0.39] \quad 0.26^{* *}[0.12-0.54]$

$0.20^{* *}[0.14-0.29] \quad 0.28^{* *}[0.16-0.49]$

Place of residence

Urban (R)

Rural

$1.86^{* *}[1.51-2.30]$

$1.06[0.83-1.35]$

$1.97^{* *}[1.52-2.56] \quad 1.35[0.94-1.92]$

$1.42^{* *}[1.16-1.77] \quad 1.05[0.82-1.34]$

Ecological belt

Mountain (R)

Hill

$0.64 * * 0.51-0.81]$

$0.90[0.70-1.15]$

$0.65^{* *}[0.49-0.85] \quad 0.67^{*}[0.49-0.91]$

$0.54^{* *}[0.37-0.79] \quad 0.80[0.54-1.18]$

Terai

$0.54^{* *}[0.43-0.69]$

$0.51 * * 0.37-0.72]$

$0.53^{* *}[0.40-0.71] \quad 0.67[0.43-1.03]$

$0.66^{*}[0.46-0.94]$

0.84 [0.53-1.33]

Household food security status

Food secure (R)

Moderately food insecure

NA

NA

NA

NA

NA

$1.40 * *$ [1.02-1.95] 0.86 [0.58-1.29]

$1.36^{* *}[1.07-1.71] \quad 0.98[0.75-1.28]$

Severely food insecure

NA

$1.68^{* *}[1.28-2.21] \quad 1.07[0.75-1.53]$

$1.76^{* *}[1.37-2.26] \quad 1.10[0.82-1.47]$

Access of drinking water

Unimproved (R)

Improved

$0.90[0.76-1.06]$

$1.19[0.98-1.44]$

$0.67[0.51-0.88]$

$0.96[0.68-1.34]$

$0.72[0.48-1.07]$

$0.82[0.53-1.29]$

Access of toilet

$$
\text { Unimproved (R) }
$$

Improved

$0.50^{* *}[0.41-0.61]$

$0.83[0.59-1.17]$

$0.65^{* *}[0.51-0.81] \quad 1.27[0.91-1.77]$

$0.49^{* *}[0.38-0.62] \quad 0.64{ }^{* *}[0.46-0.88]$

Maternal characteristics

Age of mother

$1.05^{*}[1.03-1.06]$

$0.97[0.95-0.99]$

$1.03 *[1.01-1.05] \quad 0.97[0.94-1.01]$

$1.02 *$ [1.00-1.03] 0.99 [0.96-1.02]

Years of schooling of mother

$0.87^{* *}[0.85-0.88]$

$0.92 * * 0.89-0.95]$

$0.92 * *[0.89-0.94] \quad 1.00[0.65-1.05]$

$0.91^{* *}[0.89-0.93] \quad 0.98$ [0.95-1.01]

Number of living children

$1.65^{* *}[1.51-1.79]$

1.12 [0.96-1.32]

$1.39 * *[1.23-1.58] \quad 1.05[0.86-1.28]$

$1.50^{* *}[1.33-1.70] \quad 1.17$ [0.95-1.44]

No (R) 
Table 3 Determinants of stunting in children aged 0-59 months (Continued)

\begin{tabular}{|c|c|c|c|c|c|c|}
\hline \multirow[t]{2}{*}{ Background characteristics } & \multicolumn{6}{|c|}{ Odd ratios of stunting (height for age $<-2$ SD) } \\
\hline & \multicolumn{2}{|l|}{2006} & \multicolumn{2}{|l|}{2011} & \multicolumn{2}{|l|}{2016} \\
\hline Yes & $1.45^{* *}[1.21-1.74]$ & $0.98[0.80-1.21]$ & $1.25[0.96-1.62]$ & $0.83[0.59-1.17]$ & $1.44^{* *}[1.20-1.73]$ & $1.27^{*}[1.01-1.60]$ \\
\hline \multicolumn{7}{|l|}{ Mother BMI } \\
\hline \multicolumn{7}{|c|}{ less than 18.5/underweight (R) } \\
\hline 18.5 and above & $1.35^{* *}[1.16-1.58]$ & $1.19[0.98-1.44]$ & $1.42^{* *}[1.10-1.83]$ & $1.30[0.93-1.81]$ & $1.59^{* *}[1.23-2.04]$ & $1.23[0.94-1.60]$ \\
\hline \multicolumn{7}{|l|}{ Mother anemia } \\
\hline \multicolumn{7}{|l|}{ No (R) } \\
\hline Yes & $1.12[0.97-1.30]$ & $1.24^{*}[1.04-1.48]$ & $1.06[0.86-1.30]$ & $0.95[0.74-1.23]$ & $1.01[0.84-1.24]$ & $0.90[0.72-1.14]$ \\
\hline \multicolumn{7}{|l|}{ Child characteristics } \\
\hline Age of child & $2.11 * *[1.94-2.29]$ & $2.24^{* *}[1.96-2.56]$ & $1.80^{* *}[1.59-2.03]$ & $2.58^{* *}[2.14-3.11]$ & $1.61^{* *}[1.44-1.80]$ & $1.58^{* *}[1.32-1.90]$ \\
\hline \multicolumn{7}{|l|}{ Sex of child } \\
\hline \multicolumn{7}{|l|}{ Boys (R) } \\
\hline Girls & $1.05[0.91-1.21]$ & $1.00[0.85-1.17]$ & $0.92[0.77-1.10]$ & $0.88[0.71-1.10]$ & $0.98[0.81-1.20]$ & $0.95[0.76-1.17]$ \\
\hline Birth order & $1.17^{* * *}[1.13-1.21]$ & $1.11^{*}[1.02-1.20]$ & $1.00[1.00-1.01]$ & $1.14[1.03-1.26]$ & $1.15^{* *}[1.09-1.21]$ & 0.99 [0.89-1.10] \\
\hline \multicolumn{7}{|l|}{ Size at the time of birth } \\
\hline \multicolumn{7}{|l|}{ Average or larger (R) } \\
\hline Below average & $1.64^{* *}[1.37-1.946]$ & $1.64^{* *}[1.34-2.00]$ & $1.67^{* *}[1.29-2.18]$ & $1.55^{* *}[1.19-2.02]$ & $1.64^{* *}[1.31-2.05]$ & $1.60^{* *}[1.25-2.04]$ \\
\hline \multicolumn{7}{|l|}{ Anemia } \\
\hline \multicolumn{7}{|l|}{ No (R) } \\
\hline Yes & $1.01[0.87-1.17]$ & $1.32^{* *}[1.12-1.56]$ & $1.17[0.95-1.43]$ & $1.59^{* *}[1.25-2.02]$ & $1.30^{* *}[1.06-1.61]$ & $1.40^{* *}[1.12-1.75]$ \\
\hline
\end{tabular}

breastfed until 24 months, breastfeeding gradually declines with child age [33]. Children who had a low birth weight (less than $2.5 \mathrm{~kg}$ ) were 1.5 times more likely to be stunted later in life than children of average or greater birth weight. The observed association between stunting and birth weight is consistent with other studies conducted in developing countries [34-38]. This link could be explained by the greater likelihood of low birth weight children to contract infections like diarrhea and acute respiratory infection. These infections may make the child more susceptible to later complications associated with stunting.

Child anemia was another determinant for stunting; results suggest that anemic children were 1.3 to 1.6 times more likely to be stunted than non-anemic children. Other studies have similarly found childhood anemia to be a significant determinant for stunting [39-42]. The link between anemia and stunting may be caused by anemia's role in limiting children's physical growth $[43,44]$ and iron supplementation could be used to reduce childhood stunting [45].

The findings of this study have policy implications as they provide a clear depiction of the trends and determinants of stunting from 3 nationally representative surveys over a 15 year period. Policy makers and planners can use evidence from this study to formulate feasible and culturally appropriate interventions to reduce stunting in Nepal. Though this paper explores determinants of stunting from the last 15 years of data, it is not free from limitations. The analyses are based on crosssectional survey data; thus, we were unable to assess the causal relationship between stunting and socioeconomic confounders.

\section{Conclusion}

The prevalence of stunting in Nepal remains among the highest of developing countries. This study highlights risk factors for stunting, including household wealth quintile, number of years of mother's schooling, child age, child size at birth, and child anemia. In addition to the policies and programs aimed at improving maternal and child nutrition, equal focus should be given to improving mothers' education. Findings also suggest the importance of addressing income inequality when implementing nutrition interventions.

\section{Additional files}

Additional file 1: Table S1. Prevalence of stunting $(<-2 S D)$ among children aged 0-59 months in 2006. (DOCX 16 kb)

Additional file 2: Table S2. Prevalence of stunting ( $<-2 S D)$ among children aged 0-59 months in 2011. (DOCX $16 \mathrm{~kb}$ )

Additional file 3: Table S3. Prevalence of stunting (<-2SD) among children aged 0-59 months in 2016. (DOCX 16 kb) 
Additional file 4: Table S4. Odd ratios of stunting (height for age < -2SD) in 2006. (DOCX $15 \mathrm{~kb}$ )

Additional file 5: Table S5. Odd ratios of stunting (height for age < -2SD) in 2011. (DOCX $14 \mathrm{~kb}$ )

Additional file 6: Table S6. Odd ratios of stunting (height for age < -2SD) in 2016. (DOCX $14 \mathrm{~kb})$

\section{Abbreviations}

BMI: Body Mass Index; HFIAS: Household Food Insecurity Scale; MSNP: MultiSectoral Nutrition Plan; NDHS: Nepal Demographic and Health Survey; OR: Odds Ratio; PPS: Probability proportion-to- size; SDG: Sustainable Development Goal; STATA: Software for Statistics and Data Science

\section{Acknowledgements}

We would like to thank Emily Satinsky from the University of Maryland College Park, Global Mental Health and Addiction Program, USA for reviewing and revising the final manuscript.

\section{Authors' contributions}

RPA and NU designed the study. RPA, MLS, and AA analyzed data and prepared the first draft. All authors reviewed multiple versions of the manuscript and read and approved the final version for submission.

\section{Funding}

Not applicable.

\section{Availability of data and materials}

The datasets used in this study are available from the corresponding author upon request.

\section{Ethics approval and consent to participate}

The study involved secondary analysis of publicly available data. Thus, independent ethical approval was not needed. However, the first author received permission from dhsprogram.com to use the data for analysis.

\section{Consent for publication}

Not applicable.

\section{Competing interests}

The authors declare that they have no competing interests.

\section{Author details}

'Padma Kanya Multiple Campus, Tribhuvan University, Kathmandu Nepal and Helen Keller International Nepal, Lalitpur, Nepal. ${ }^{2}$ FHI360, Kathmandu, Nepal. ${ }^{3}$ University of Melbourne, Melbourne, Australia. ${ }^{4}$ Transcultural Psychosocial Organization Nepal, Kathmandu, Nepal.

Received: 17 December 2018 Accepted: 26 June 2019

Published online: 05 August 2019

\section{References}

1. WHO. World health statistics 2011. Geneva: World Health Organization; 2011.

2. WHO. World health statistics 2014. Geneva: World Health Organization; 2014.

3. Victora CG, Adair L, Fall C, Hallal PC, Martorell R, Richter $L$, et al. Maternal and child undernutrition: consequences for adult health and human capital. Lancet. 2008:371:340-57.

4. de Onis M, Branca F. Childhood stunting: a global perspective. Mat Child Nutr. 2016:12(Suppl 1):12-26.

5. Woldehanna T, Behrman JR, Araya MW. The effect of early childhood stunting on children's cognitive achievements: evidence from young lives Ethiopia. Ethiop J Heal Dev. 2017;31(2):75-84

6. IFPRS. Global nutrition report 2016: from promise to impact: ending malnutrition by 2030. Washington, DC: International Food Policy Research Institute (IFPRS); 2016.

7. WHO. Global nutrition targets 2025: policy brief series (WHO/NMH/NHD/14. 2). Geneva: World Health Organization; 2014

8. UNDP. The sustainable development goals report 2017. New York: United Nations; 2017

9. Group UWWB. Joint Child Malnutrition Estimates: United Nations Children's Fund, the World Health Organization and World Bank Group; 2017.
10. UNICEF. The state of the world's children, a fair chance for every child. New York: United Nations Children's Fund (UNICEF); 2016.

11. Paudel R, Pradhan B, Wagle RR, Pahari DP, Onta SR. Risk factors for stunting among children: a community based case control study in Nepal. Kathmandu Univ Med J. 2012;39(3):18-24.

12. Adhikari D, Khatri RB, Paudel YR, Poudyal AK. Factors associated with underweight among under-five children in eastern Nepal: communitybased cross-sectional study. Public Health. 2017;5:350.

13. Tiwari R, Ausman LM, Agho KE. Determinants of stunting and severe stunting among under-fives: evidence from the 2011 Nepal Demographic and Health Survey. BMC Pediatrics. 2014;14:239.

14. NPC. Multi-sector nutrition plan, for accelerating the reduction of maternal and child under-nutrition in Nepal 2013-2017 (2023). Kathmandu: Government of Nepal, National Planning Commission; 2012.

15. Devkota MD, Adhikari RK, Upreti SR. Stunting in Nepal: looking back, looking ahead. Matern Child Nutr. 2016;12(Suppl Suppl 1):257-9.

16. MOH, New ERA, Inc. II. Nepal Demographic and Health Survey 2016. Kathmandu: Ministry of Health, new ERA, and ICF international, Calverton. p. 2016.

17. WHO. WHO child growth standards: length/height-for-age, weight-for-age, weight-for-length, weight-for height and body mass index-for-age: methods and development. Geneva: World Health Organization; 2006.

18. Coates J, Anne S, Paula B. Household food insecurity access scale (HFIAS) for measurement of household food access: Indicator quide (v. 3). Washington, D.C: Food and Nutrition Technical Assistance Project, Academy for Educational Development; 2007.

19. Cunningham K, Headey D, Singh A, Karmacharya C, Rana PP. Maternal and child nutrition in Nepal: examining drivers of progress from the mid-1990s to 2010s. Glob Food Sec. 2017:13:30-7.

20. WB. Accelerating progress in reducing maternal and child undernutrition in Nepal. Kathmandu: The World Bank; 2012.

21. Akombi BJ, Agho KE, Hall JJ, Wali N, Renzaho A, Merom D. Stunting, wasting and underweight in sub-Saharan Africa: a systematic review. Int J Environ Res Public Health. 2017;14(8):863.

22. Sarma H, Khan JR, Asaduzzaman M, Uddin F, Tarannum S, Hasan MM, et al. Factors influencing the prevalence of stunting among children aged below five years in Bangladesh. Food Nutr Bull. 2017:38(3):291-301.

23. Nahar B, Ahmed T, Brown KH, Hossain Ml. Risk factors associated with severe underweight among young children reporting to a Diarrhoea treatment Facility in Bangladesh. J Health Popul Nutr. 2010;28(5):476-83.

24. Urke HB, Bull T, Mittelmark MB. Socioeconomic status and chronic child malnutrition: wealth and maternal education matter more in the Peruvian Andes than nationally. Nutr Res. 2011;31(10):741-7.

25. Jesmin A, Yamamoto SS, Malik AA, Haque MA. Prevalence and determinants of chronic malnutrition among preschool children: a cross-sectional study in Dhaka City, Bangladesh. J Health Popul Nutr. 2011;29(5):494-9.

26. Ayana AB, Hailemariam TW, Melke AS. Determinants of acute malnutrition among children aged 6-59 months in public hospitals, Oromia region, West Ethiopia: a case-control study. BMC Nutrition. 2015;1(1):34.

27. Janevic T, Petrovic O, Bjelic I, Kubera A. Risk factors for childhood malnutrition in Roma settlements in Serbia. BMC Public Health. 2010;10:509.

28. Khor GL, Sharif ZM. Dual forms of malnutrition in the same households in Malaysia - a case study among Malay rural households. Asia Pac J Clin Nutr. 2003:12(4):427-38

29. Joshi N, Agho KE, Dibley MJ, Senarath U, Tiwari K. Determinants of inappropriate complementary feeding practices in young children in Nepal: secondary data analysis of Demographic and health Survey 2006. Matern Child Nutr. 2012:8:45-59.

30. Khan NC, Tuyen LD, Ngoc TX, Duong PH, Khoi HH. Reduction in childhood malnutrition in Vietnam from 1990 to 2004. Asia Pac J Clin Nutr. 2007;16(2): $274-8$

31. Hien NN, Kam S. Nutritional status and the characteristics related to malnutrition in children under five years of age in Nghean, Vietnam. J Prev Med Public Health. 2008;41(4):232-40

32. Ulak M, Chandyo RK, Mellander L, Shrestha PS, Strand TA. Infant feeding practices in Bhaktapur, Nepal: a cross-sectional, health facility based survey. Int Breastfeed J. 2012;7(1):1

33. Dhungana GP. Nutritional status and the associated factors in under five years children of Lamjung, Gorkha and Tanahun districts of Nepal. Nepalese J Stat. 2017;1:15-8

34. Rahman MS, Howlader T, Masud MS, Rahman ML. Association of low-Birth Weight with malnutrition in children under five years in Bangladesh: do 
Mother's education, socio-economic status, and birth interval matter? PLoS One. 2016;11(6):e0157814.

35. Aryastami NK, Shankar A, Kusumawardani N, Besral B, Jahari AB, Achadi E. Low birth weight was the most dominant predictor associated with stunting among children aged 12-23 months in Indonesia. BMC Nutrition. 2017;3(1):16.

36. WHO. World health statistic. Geneva: World Health Organization; 2009.

37. Islam MM, Alam M, Tariquzaman M, Kabir MA, Pervin R, Begum M, et al. Predictors of the number of under-five malnourished children in Bangladesh: application of the generalized poisson regression model. BMC Public Health. 2013;13:11

38. Khan Khattak MMA, Ali S. Malnutrition and associated risk factors in preschool children (2-5 years) in district Swabi (NWFP)-Pakistan. J Med Sci. 2010;10:34-9.

39. Soares Magalhães RJ, Clements ACA. Mapping the risk of Anaemia in preschool-age children: the contribution of malnutrition, malaria, and helminth infections in West Africa. PLoS Med. 2011;8(6):e1000438.

40. Awasthi S, Das R, Verma T, Vir S. Anemia and undernutrition among preschool children in Uttar Pradesh, India. Indian Pediatrics. 2003;40:985-90.

41. Leite MS, Cardoso AM, Coimbra CE, Welch JR, Gugelmin SA, Lira PCl, et al. Prevalence of anemia and associated factors among indigenous children in Brazil: results from the first National Survey of indigenous People's health and nutrition. Nutr J. 2013;12:69.

42. Medhin G, Hanlon C, Dewey M, Alem A, Tesfaye F, Worku B, et al. Prevalence and predictors of undernutrition among infants aged six and twelve months in Butajira, Ethiopia: the P-MaMiE birth cohort. BMC Public Health. 2010:10, 27.

43. WHO. Iron Deficiency Anaemia Assessment, Prevention, and Control. A guide for Programme Managers. Washington DC: World Health Organization; 2001

44. Briend A, Hoque BA, Aziz KM. Iron in tubewell water and linear growth in rural Bangladesh. Arch Dis Child. 1990;65:224-37.

45. Angeles IT, Schultink WJ, Matulessi P, Gross R, Sastroamidjojo S. Decreased rate of stunting among anemic Indonesian preschool children through iron supplementation. Am J Clin Nutr. 1993;58(3):339-42.

\section{Publisher's Note}

Springer Nature remains neutral with regard to jurisdictional claims in published maps and institutional affiliations.

Ready to submit your research? Choose BMC and benefit from:

- fast, convenient online submission

- thorough peer review by experienced researchers in your field

- rapid publication on acceptance

- support for research data, including large and complex data types

- gold Open Access which fosters wider collaboration and increased citations

- maximum visibility for your research: over $100 \mathrm{M}$ website views per year

At $\mathrm{BMC}$, research is always in progress.

Learn more biomedcentral.com/submissions 